\title{
Erratum to: Unimodal pattern of soil hydrophobicity along an altitudinal gradient encompassing Mediterranean, temperate, and alpine ecosystems
}

\author{
Giuliano Bonanomi • Salvatore A. Gaglione • \\ Vincenzo Antignani • Gaspare Cesarano
}

Published online: 15 October 2016

(C) Springer International Publishing Switzerland 2016

\section{Erratum to: Plant and Soil \\ DOI 10.1007/s11104-016-3020-0}

The published online paper unfortunately contains error. The capturing of the Author name Bonanomi Giuliano was swapped in $\mathrm{xml}$ as well as in PDF. Bonanomi should be captured as surname and Giuliano should be captured as given name. However, this now corrected and is not anymore present in the published copies of the article.

The online version of the original article can be found at http://dx.doi.org/10.1007/s11104-016-3020-0

G. Bonanomi $(\bowtie) \cdot$ S. A. Gaglione $\cdot$ G. Cesarano

Dipartimento di Agraria, University of Naples Federico II, via Università, 100 Naples, Italy

e-mail: giuliano.bonanomi@unina.it

V. Antignani

Department of Biology, Division of Natural Science, Bob Jones University, Build Faith, Challenge Potential, Follow Christ,

Greenville, USA 